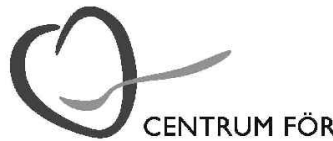

KLINISK PröVning av Livsmedel

\title{
Identifying and marketing the health benefits of foods
}

\author{
Birgitta Sundberg and Johan Olsson
}

Centre for Clinical Trials of Foodstuffs, KPL, Uppsala University, Uppsala, Sweden

A unique centre for clinical trials of foodstuffs (in Swedish: Centrum för Klinisk Prövning av Livsmedel - KPL) has been created in Uppsala. This centre specializes in performing qualityassured clinical evaluation of the physiological health effects of foods and food ingredients. The centre was inaugurated in spring 2002, but Uppsala has already had long experience in this sector, since clinical trials of foodstuffs have been performed here for 30 years. The centre forms one of the institutions at Uppsala University, but is also being financed by the Swedish University of Agricultural Sciences (SLU), Uppsala County Administration and Uppsala County Council. The Swedish Agency for Innovation Systems is also providing some financing for the centre.

Lifestyle-related health complaints such as the "metabolic syndrome" are becoming increasingly common. They involve a great deal of human suffering, along with high costs of social welfare for society. Preventive measurements in the form of improved diet and increased physical activity are very important in exposed groups. In addition to this, other trends can be noted in developed countries, where interest in personal health and longterm wellbeing makes people conscious about the food they eat. Academic research and the food industry in the USA and Japan have in many respects been leading the way in the development of new foodstuffs to meet these demands.

In Sweden, the food industry is now allowed to label foodstuffs with specific health claims, providing that the claims are based on independent and controlled clinical tests performed on humans. Primaliv $^{\circledR}$, produced by Skånemejerier, was the first product to carry such claims. This labelling provides an exceptional opportunity both for con- sumers to be able to control and optimize their diet and for the food industry to make commercial use of research and product development.

The results from clinical trials increase the available knowledge about a product and this can also be used for further product development or to improve product safety. The results from clinical trials may form the basis for patent applications. This can strengthen a company trademark and increase the credibility to the consumer, investors and authorities. New knowledge about food products will be sought by the consumer, the research society, industry and business enterprises, as well as society at large.

KPL's vision is to be the natural place to which companies and research groups turn when they want to evaluate specific physiological and health effects of a foodstuff or a food ingredient. KPL specializes in this type of activity, with several organizational features to ensure quality and effectiveness. First, a scientific board, with very broad expertise in the area of clinical trials of foodstuffs, and geographically spread over the country, is affiliated to the centre. The areas of expertise represented include raw materials including bioactive components, toxicology, clinical nutrition research and clinical trials of foodstuffs, to mention but a few. The members of the scientific board are:

- Per Åman, Professor in Plant Foods, SLU

- Bengt Vessby, Visiting Professor in Clinical Nutrition Research, Uppsala University

- Göran Hallmans, Professor in Nutrition Research, Umeå University

- Ingvar Bosaeus, Associate Professor, University of Gothenburg

- Åke Nilsson, Professor in Specialist Medicine Clinic, Malmö General Hospital 
- Agneta Oskarsson, Professor in Toxicology, SLU

- Mai-Lis Hellenius, Associate Professor, Karolinska Institute (KI).

In collaboration with the staff of KPL and the scientific board, designs will be drawn up for different clinical tests, with emphasis on the scientific quality of the studies and their relevance in relation to the specific health effect that the customer wants to investigate. Once the designs of the clinical tests are ready, KPL will start to perform the studies in a fast and efficient manner, as the necessary resources are already at hand at the centre. Experienced staff (i.e. doctors, nurses and a statistician) have been recruited and other facilities such as clinical reception rooms, a laboratory and a diet preparation kitchen are ready. Thus, as stated in KPL's business plan, the target activity of the centre is to perform controlled clinical trials of the health effects of foodstuffs and food ingredients on humans in a professional and user-friendly way. During autumn 2002, it is expected that KPL will accomplish six clinical trials.

The top-level personnel of KPL include an executive director, Johan Olsson, and a project manager, Birgitta Sundberg. Both Johan and Birgitta have worked at SLU. Johan has a doctoral degree in Microbiology and Birgitta a doctoral degree in Food Science specializing in dietary fibre. She is also well known as the executive director of Uppsala Food and Nutrition Centre (ULC).

A reference group, which is intended to support the executive director and the activities of KPL, is also associated with the centre.

The board and the executive director will work together on overall direction and strategies. The board of KPL has the following members:

- Ulf Henricsson, Uppsala County Administration (chairman)

- Nils-Georg Asp, Managing Director of Swedish Nutrition Foundation (SNF)

- Margaretha Jägerstad, Professor at SLU
- Agneta Dreber, Director General of the Swedish Food Federation (Livsmedelsindustriföretagen)

- Ingvar Sjögren, Director of Health and Medical Services at Uppsala County Council

- Christian Berne, Professor at Uppsala University.

In addition to clinical trials, KPL plans to function as a centre of expertise, where high-quality research and education is performed to increase current knowledge on the relationship between diet and health in humans.

KPL will work to improve and develop new analytical methods and techniques for scientific documentation of the health effects of foodstuffs. KPL's vision is to provide researchers with new ways of advancement as well as with research positions within the area. KPL will also work to improve communication between the food industry and different academic units active in the food area.

Clinical trials of the health effects of foodstuffs comprise many complex scientific problems and can therefore be generally regarded as difficult to complete while retaining the scientific quality of the results. There is a long practical experience of clinical trials of foodstuffs in Uppsala. The connections with the National Food Administration and the Medical Product Agency, together with the universities in city, make the geographical location of KPL advantageous. However, there are research areas that are not covered in the Uppsala region. KPL will act as a national resource, collecting national expertise in the area of food for mutual exchange of services, ideas and resources. This will strengthen the position of Sweden in this field.

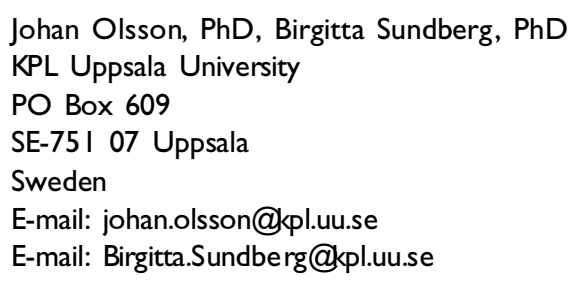

